This item was submitted to Loughborough's Research Repository by the author.

Items in Figshare are protected by copyright, with all rights reserved, unless otherwise indicated.

\title{
Social hierarchies: a laboratory study on punishment patterns across networks
}

PLEASE CITE THE PUBLISHED VERSION

https://doi.org/10.1111/ecin.12766

\section{PUBLISHER}

Wiley () Western Economic Association International

VERSION

AM (Accepted Manuscript)

\section{PUBLISHER STATEMENT}

This is the peer reviewed version of the following article: FATAS, E., MELENDEZ-JIMENEZ, M.A. and SOLAZ, $\mathrm{H}$., 2019. Social hierarchies: a laboratory study on punishment patterns across networks. Economic Inquiry, 58(1), pp. 104-119, which has been published in final form at https://doi.org/10.1111/ecin.12766. This article may be used for non-commercial purposes in accordance with Wiley Terms and Conditions for Use of SelfArchived Versions

\section{LICENCE}

CC BY-NC-ND 4.0

\section{REPOSITORY RECORD}

Fatas, Enrique, Miguel A. Melendez-Jimenez, and Hector Solaz. 2019. "Social Hierarchies: A Laboratory Study on Punishment Patterns Across Networks”. Loughborough University. https://hdl.handle.net/2134/37308. 


\title{
Social hierarchies
}

A laboratory study on punishment patterns across networks*

\author{
Enrique Fatas ${ }^{+}$ \\ Loughborough University
}

and

Universidad del Rosario

Universidad del Rosario
Miguel A. Meléndez-Jiménez

Universidad de Málaga
Hector Solaz

University of Essex

\begin{abstract}
We experimentally study punishment patterns across network structures, and their effect on cooperation. In a repeated public goods setting, subjects can only observe and punish their neighbors. Centralized structures (like the star network) outperform other incomplete networks and reach contribution levels like the ones observed in a complete network. Our results suggest that hierarchical network structures with a commonly observed player benefit more from sanctions not because central players punish more, but because they follow, and promote, different punishment patterns. While quasi-central players in other incomplete architectures (like the line network) retaliate, and get trapped in the vicious circle of antisocial punishment, central players in the star network do not punish back, increase their contributions when sanctioned by peripheral players, and sanction other participants in a prosocial manner. Our results illustrate recent field studies on the evolutionary prevalence of hierarchical networks. We document a network-based rationale for this positive effect in an identity-free, fully anonymous environment.
\end{abstract}

JEL Classification Numbers: C72, C91, C92, D90, H41.

Key Words: public good experiments, networks, monitoring, punishment.

\footnotetext{
* Enrique Fatas acknowledges support from the ESRC Network for an Integrated Behavioral Science (NIBS). Miguel A. MeléndezJiménez acknowledges financial support from the Spanish Ministry of Economy and Competitiveness through Project ECO201452345-P and from the Regional Government of Andalusia through Project SEJ2011-8065. Different versions of the paper have largely benefited from comments from Antonio J. Morales, Gary Charness, Abhijt Ramalingam, Andrew Sheltzer and Michael Spagat. The usual disclaimer applies.

+ Corresponding author: E.Fatas@lboro.ac.uk, School of Business and Economics, Loughborough University.
} 


\section{Introduction}

Social dilemmas are ubiquitous and a serious challenge for groups, organizations and societies. Overpopulation, pollution, resource depletion, low turnout rates or poor team performance in firms are some well-known examples of situations in which the tension between individual and collective interest generates sub-optimal group outcomes. An archetypical example of a relevant social dilemma is team production in organizations. The outcome produced by a team of workers within a firm typically depends on the level of effort exerted by each worker and, if rewards do not depend on individual efforts but on the outcome of the group, workers may have incentives to free-ride on their team-mates. Starting with Yamagishi (1986), Olstrom et al (1992) and Fehr and Gachter (2000, 2002), a vast behavioral literature has studied how individually costly sanctions may alleviate the under provision of public goods, or increase team production. Team production closely resembles the framework proposed by Fehr and Gächter (2000) if workers can formally or informally verify the level of efforts exerted by every other team member, and subsequently monitor and punish them. The interesting result from this literature is that even when punishment can be reasonably considered a second order public good, a relatively small proportion of strong reciprocators punishing free riders (a social type of punishment) suffices to improve social welfare in laboratory experiments. ${ }^{1}$

The bad news for the positive effect of sanctions on public good provision is its context dependence, as conditional cooperation patterns are very sensible to the structural characteristics of the social dilemma, as Croson et al $(2005,2015)$ document. The existence of a significant fraction of strong reciprocators does not increase cooperation if individuals can retaliate in additional counter punishment stages, as Cinyabuguma et al (2006) and Nikiforakis (2008) show. The evidence suggests that strong reciprocators are not the only ones willing to punish. The balance between social punishment (targeting free-riders) and anti-social punishment (targeting cooperators) crucially determines the success of sanctions, being the balance mediated by the culture dependent norms taken by participants to the lab. In an experiment run in 16 different locations, Herrmann et al (2008) document the negative correlation between the extent of antisocial punishment and the welfare enhancing effect of sanctions. ${ }^{2}$ Fatas and Mateu (2015) show that high levels of antisocial punishment may diminish cooperation in some societies only for some public good production functions, as antisocial sanctions vanish when contributions to the public good are complementary, rather than substitutes. ${ }^{3}$

\footnotetext{
${ }^{1}$ The exploration of other structural features of the canonical public goods game has covered several issues. Chaudhuri (2011) surveys public goods experiments, with a special emphasis on monetary punishment.

2 Antisocial punishment generates this negative effect even in one-shot experiments, see Gächter and Herrmann (2009).

${ }^{3}$ Punishment may have very different effects in other social dilemmas, mediated by other behavioral drivers. Calabuig et al (2016) show that punishment only increases social welfare when punishers receive a much higher endowment in trust games (a 'big stick', using their terms).
} 
Conditional cooperation patterns are not only shaped by the structure of the game and culturally dependent social norms. In many real-world situations, the spatial structure of social interactions between agents, either vertical (hierarchical) or horizontal (non-hierarchical, as in the Fehr and Gächter (2000) paradigm already discussed), plays a crucial role. The positive impact of sanctions on public good provision may increase (decrease) if the punishment institution is endogenously chosen by players (see Sutter et al, 2010) or exogenously imposed (see Fatas et al, 2010b). In the team production game captured by Fehr and Gächter (2000), a pre-requisite for the success of individually costly sanctions is that team members should have not only the will, but also the means to punish other team members: information about their individual efforts and access to the punishment technology. This, however, rarely occurs in real-life settings, in which the network structure of teams varies, and many times fails to give each team member the possibility of monitoring and sanctioning every other player. As a rule, workers only directly interact with a small subset of firm employees, those connected with them through a local organizational network.

In this paper, we contribute to the analysis of networks in public good games, with a special interest in hierarchical networks. Rather than following the horizontal and complete interaction considered in most papers mentioned above, in our setting individuals make decisions in complete and incomplete networks. Participants in our experiment receive information about the decisions made by others, and get an opportunity to sanction them, depending on the network structure (controlled by our between-subjects design) and their position (randomized within each treatment). In our framework, networks generate heterogeneous agents, being an agent's type determined by her number of links (i.e., her degree in the network). In a nutshell, our experimental design creates systematic variations of information and punishment opportunities.

Inspired by Herrmann et al (2008), we are particularly interested in studying the balance between social and anti-social punishment, exerted by different types (or degrees) of players in a variety of hierarchical and non-hierarchical networks. We identify and rationalize how different, exogenously imposed, social networks perform, and why, characterizing the underlying behavioral patterns of players' types in a stylized social dilemma. In our experiment, subjects repeatedly interact in fixed undirected and connected networks, in groups of four players. Each round, subjects first play a linear public goods game (the voluntary contribution mechanism, or VCM) and, then, they may punish other players at a cost. The network structure determines both information (the number of players they monitor at the end of the first stage) and punishment opportunities (the participants they may punish in the second stage). We consider four between subjects treatments (or network structures): the complete, the circle, the line and the star network. The complete network acts as the benchmark case (with full observability and full bilateral punishment opportunities). The remaining networks are incomplete and, therefore, observability 
and punishment are restricted. In all networks, participants are randomly assigned to types, and types and composition of teams never change.

Relative to other incomplete networks, we find that hierarchical networks (like the star), where central players can monitor and punish all peripheral players, being monitored and potentially punished by them, are associated with higher levels of cooperation, lower levels of punishment, and significant welfare gains. We identify three crucial elements in this superiority of the star network. First, only in hierarchical networks, central players choose to punish in a pro-social way, disciplining free riders at a high personal cost (as both central and peripheral players receive the same endowment). Second, central players do not retaliate when punished by peripheral players in the star network. Third, peripheral players in the star network follow prosocial central players, and adjust their contributions up when punished. These three elements are not present in the other incomplete network structures we study (the circle and the line): central players exhibit anti-social punishment and central and peripheral players in the line network retaliate when punished. ${ }^{4,5}$

Our results have direct implications in several contexts, including organizational design. In many real-world organizations, establishing direct interaction structures between agents (allowing individuals to observe and punish each other) is costly. Our complete network, while performing as well as the star network in terms of public good provision, is in this sense costlier. Our results suggest that incomplete networks with identical or similar number of links may generate very different outcomes, as some incomplete networks (like the line or the circle) are outperformed by others (the star network). Organizations could efficiently allocate a limited number of links across employees creating hierarchical networks. The presence of (at least) one central player (a subject able to monitor and being monitored by others) significantly improves team production in our setting.

The rest of the paper is organized as follows. Section 2 reviews the related literature. Section 3 explains the experimental design and procedures. Section 4 reports on the experimental results. Section 5 concludes.

\section{Social hierarchies}

In this section, we briefly review recent experimental studies analyzing centralized structures in social dilemmas, in different disciplines, and discuss the lessons and limitations. A few studies show that cooperative subjects gain a higher status both among other participants in

\footnotetext{
${ }^{4}$ Public good provision in the complete network is close to the one we observe in the star (with twice the number of links). In sharp contrast with the central players in the star, individuals in the complete network (also able to punish and be punished by all other participants) do retaliate.

${ }^{5}$ Kosfeld and Rustagi (2015) conduct a social dilemma experiment in Ethiopia in which real-world leaders can punish group members as a third party, and show that different types of leaders (pro-social and anti-social) generate different group cooperation outcomes. Harrel and Simpson (2016) obtain similar results in a laboratory experiment.
} 
the experiment (Hardy and Van Vugt, 2006) and by third-party observers (Willer, 2009). ${ }^{6}$ The role of status relates to Tsai (2007), who studies informal accountability and local public good provision in rural China, finding that the more local authorities are embedded in the social (community) network, the higher the level of local public good provision. ${ }^{7}$ Tsai (2007) argues that " a local official with sufficient moral standing may also be more able to persuade leaders of the community solidarity group to use their own moral authority to win over particularly stubborn opponents of the policy". Similarly, Lierl (2016) shows experimentally how the effectiveness of mutual sanctioning depends on how the provider of the public good (a third party able to extract rents) is connected in the sanctioning network.

Our results are well aligned with recent findings in political science. In experimental social dilemmas run in Uganda, Habyarimana et al (2007) and Grossman and Baldassarri (2012) show how central players may be ready to sacrifice their own payoffs to discipline others when acting as central authorities. Baldassarri and Grossman (2013) show that community leaders exhibit a greater generosity toward in-group members. ${ }^{8}$ A notable, and to some extent natural, difference with our experiment is that in the field experiments run in Uganda types are not randomly assigned, as central players are chosen among those leaders already elected in preexistent social networks, with some pre-existent personal knowledge. Our experiment (with higher levels of control over exogenous factors) aims, first, to understand if these findings are replicable in an abstract environment in which identical participants are randomly assigned to types, keeping at bay different individual characteristics of leaders (central players). Second, we identify punishment patterns of central and peripheral players in different network structures when the number of links is identical for central (three links in both the star and the complete network) and peripheral agents (one link in the line and star network). ${ }^{9}$

Hierarchical structures may play prominent roles in self-organizing policy networks. Berardo and Scholz (2010) find that policy actors in U.S. estuaries tend to select popular actors as partners, creating a centralized structure capable of efficient information exchange, coordinating policies. ${ }^{10}$ In a related vein, the collective action model of Siegel (2009) shows that elites may trigger near-total political participation across a substantial range of network parameters only if they share strong internal motivations and a unique position within the network. Again, in our experiment participants are exogenously and randomly assigned to types, like the

\footnotetext{
${ }^{6}$ See Eisenegger et al (2012) for a similar argument to interpret the effect of testosterone on behavior in public goods games.

${ }^{7}$ Relatedly, a recent study by Grossman (2014) on rural Uganda finds that directly elected leaders are more responsive to group members as compared to appointed leaders.

${ }^{8}$ In a similar vein, Jack and Recalde (2015) run a field experiment in Bolivia and found that voluntary contributions increase when democratically elected local authorities lead by example.

9 A recent study by Bendahan et al (2015) shows experimentally that giving more power to leaders can lead to more corruption/antisocial behavior. However, this happens in contexts where the leader has the power to decide on the allocation of the outcome.

${ }^{10}$ In their study, every estuary but one has one central actor, a small number of intermediary actors and many peripheral actors, and partner selection is driven by the search of focal popular actors acting as central coordinators.
} 
central position in the star network. In this neutral context and history free environment, we document how subjects in central positions may favor collective welfare, while those individuals randomly assigned to peripheral roles accept (and positively react to) punishment only in hierarchical networks.

Our results are also consistent with a superior evolutionary dynamics of hierarchical networks, recently developed in statistical physics (Ravasz and Barabasi, 2003; Wang et al, 2009; Czaplicka et al, 2013; Mones, 2013), biology (Ma et al, 2004; Nagy et al, 2010; Flushing et al, 2011), management (Magee and Galinsky, 2008), computer science (Swai, 2013) and neuroscience (Kaiser and Hilgetag, 2010). Our study contributes to this literature by isolating how the network structure itself generates more cooperation when other (constant) factors do not blur the picture.

Our paper also contributes to the experimental literature on punishment in public goods games (see Chaudhuri, 2011, for a survey). ${ }^{11}$ Carpenter (2007) and Leibbrandt et al (2015) find that reduced monitoring may reduce public good provision in symmetric and asymmetric incomplete networks with no central player. ${ }^{12}$ Our study clearly shows the importance of a central player able to monitor all other group members. Eckel et al (2010) randomly assign central positions in star networks to either players with the highest (high-status treatment) or lowest (lowstatus treatment) score in an unrelated trivia quiz. While high-status central players are closely mimicked by peripheral players, rarely punished by central players, punishment dynamics is more intense among low-status central players, because they send and receive more punishment points, making punishment effective in increasing the provision of the public good.

Carpenter et al (2012) consider eight different networks (including connected and nonconnected, directed and undirected networks) in a strangers' matching experiment. When connected and undirected, all incomplete networks present similar contribution levels. Our very different results naturally suggest that the matching protocol matters, as stable hierarchical architectures outperform other stable incomplete networks. ${ }^{13}$ Similarly, O'Gorman et al (2009) study the case where only one player can punish all others, although not being punished (i.e., a directed star), after observing all others contributions, using a strangers' protocol in which the composition of groups changes every round. In contrast to Carpenter (2012), network positions are randomly shuffled each period. In this setting, while the directed star and the complete

\footnotetext{
11 There are also experiments on public good games played in networks without any formal sanctioning institution. For instance, Fatas et al (2010a) study how 4-person groups repeatedly play a standard linear VCM in our same four network structures, and Rosenkranz and Weitzel (2012) test in the lab Bramoulle and Kranton's (2007) model of public good games in networks. There are also experimental papers that study cooperation in prisoners' dilemma games played in networks (Kirchkamp and Nagel, 2007; Cassar, 2007), and Charness et al (2014) experimentally study games of strategic complements and games of strategic substitutes in networks (including best shot games).

12 See Eckel et al (2016) for a discussion of evolutionary behavioural drivers in public goods games.

${ }^{13}$ As in Herrmann et al (2008), the fact that we ran our experiments as repeated games, allows us to see whether different cooperation levels remain stable across groups, a possibility that is precluded in one-shot experiments. Our framework captures better many realworld networks in which groups of individuals keep a stable relationship, and repeatedly interact, over time.
} 
networks perform similarly in terms of contributions, the star does better in terms of efficiency (even when group composition is not fixed).

\section{Experimental design and procedures}

Our experimental sessions were run jointly with the treatments of Fatas et al. (2010a) FMS, hereafter. In each FMS session, after 20 rounds of play of Voluntary Contribution Mechanism (VCM) game within a network, there was a surprise restart, and participants played 20 additional rounds of a new treatment with punishment opportunities, keeping the group composition constant. ${ }^{14}$

We therefore shall briefly describe FMS's experimental design before introducing ours, which extends the VCM game by adding a second (punishment) stage. FMS consider four treatments, with 20 rounds each. A group $G$ is composed by 4 agents, and each treatment corresponds to a different network defined on $G$ that determines an organizational structure. These networks are depicted in Figure 1: The complete network (treatment $\mathrm{CO}$ ), the circle (treatment $\mathrm{CI}$ ), the line (treatment LI) and the star (treatment ST). In Figure 1, an edge between two agents represents a link. We assume that networks are undirected, i.e., if an agent is linked to another one, the latter is also linked to the former. Subjects are classified by their number of links (degree): Subjects of degree 1 (D1), degree 2 (D2) and degree 3 (D3) have, respectively, one, two and three links. Hence, the complete network consists of four D3 subjects; the circle consists of four D2 subjects; the line consists of two D2 subjects and two D1 subjects; and the star consists of one D3 subject (the center) and three D1 subjects. In all four treatments, we use a partners' matching protocol, that is, the group composition is kept constant. Moreover, each subject's position within a network is randomly determined at the beginning of the experiment and remains fixed through it.

[Figure 1 around here]

In each FMS treatment, groups repeatedly play the Voluntary Contributions Mechanism (VCM) game, and networks determine the observational structure. That is, after each round, a subject is only able to observe the individual contributions made by the group members that she is linked to. At the beginning of each round, subjects are endowed with 50 Experimental Currency Units (ECUs), and (simultaneously) allocate any fraction of their endowment to a group account, $c_{i}$, typing the number on their computer keyboard. Each ECU contributed to the group account yields a payoff of $0.5 \mathrm{ECU}$ to each group member. Each ECU not contributed by the subject is credited to the subject's private account. In any round, individual earnings (in ECU) are given by:

\footnotetext{
14 Subjects were informed that after the additional 20 rounds, the experiment would end.
} 


$$
E_{i}=50-c_{i}+0.5\left(c_{i}+\sum_{j \in G \backslash\{i\}} c_{j}\right)
$$

At the end of the round, the computer displays the subject's initial endowment, the contribution of the other group members who are linked to her, and her earnings from both the private and the group accounts. It is not difficult to see that individual $i$ 's earnings at any given round and treatment are maximized at $c_{i}=0$. Since the game is finitely repeated, there is a unique subgame perfect equilibrium, in which all members of the group contribute zero in all rounds.

At each session, once subjects had played 20 rounds of the VCM scenario studied in FMS, there was a surprise restart. The same groups of subjects played 20 rounds of our extended game that we call the PUN game (hereafter, we refer by the VCM game to the FMS scenario and by the PUN game to the scenario with punishment). ${ }^{15}$ In the PUN game, each round consists of twostages. The first stage follows exactly the VCM rules described above. At the beginning of the second stage, subjects are informed of the contribution levels of each of the other members of their group that they are linked to (i.e., their neighbors in the network). Then, they are asked to assign from zero to ten punishment points to each neighbor. Each point received reduces the firststage earnings of the subject by $10 \%$, with a maximum reduction of $100 \% .{ }^{16}$ Participants observe the aggregate number of points they receive. Punishment points are costly and the costs (in ECU) are given in Table 1 below. Let $P_{\text {in }}$ be the number of points assigned by $i$ to $n$, and $K\left(P_{i n}\right)$ be the cost to $i$ of assigning the points to $n$. Subject $i$ 's earnings in any round are:

$$
E_{i}=\left(50-c_{i}+0.5 \sum_{j \in G} c_{j}\right) \max \left\{0,\left(1-\frac{\sum_{j \in G \backslash\{i\}} P_{j i}}{10}\right)\right\}-\sum_{j \in G \backslash i\}} K\left(P_{i j}\right)
$$

[Table 1 around here]

At the end of a round, the computer displays the initial endowment, the earnings from the first stage, the total number of points received, the total cost of all points allocated, the overall earnings for both stages, and the total group contribution. ${ }^{17}$ In the unique subgame perfect equilibrium of the stage game all players contribute zero and never punish, regardless of the network. Since the game is finitely repeated, there is a unique subgame perfect equilibrium, in which all players contribute zero and never punish.

The whole experimental sessions were conducted at LINEEX (Laboratory for Research in Experimental Economics), at the University of Valencia. We recruited 144 subjects from

\footnotetext{
15 The network and the subjects' positions within the network also remained the same.

${ }^{16}$ While the majority of experimental public goods games use a constant ratio punishment technology, rather than a proportional one, we decided to use the proportional one to give participants the potential to destroy $100 \%$ of individual earnings in any round, even when this almost never happened.

${ }^{17}$ Since subjects know their earnings from the first stage, and the specific contribution of each neighbour, they may infer the aggregate contribution of the other three group members. Although D3 and D2 subjects may be considered equivalent in informational terms, they are still very different in terms of punishment: D3 subjects can punish (and be punished by) all other players of the group, whereas D2 subjects cannot.
} 
undergraduate courses in business and economics, all of them inexperienced in experimental public good games and network experiments. We ran 8 sessions (two for each treatment) and no subject participated in more than one session. Specifically, 36 subjects participated in treatment $\mathrm{CO}, 36$ subjects participated in treatment $\mathrm{CI}, 40$ subjects participated in treatment LI, and 32 subjects participated in treatment ST. Table 2 summarizes this information. On average, a session lasted around 90 minutes and subjects made on average $€ 32.68$ (including the earnings made in both games and the show-up fee of $€ 5$ ). The experiment was computerized using ZTREE (Fischbacher, 2007). A copy of the instructions, translated into English can be found in the Appendix.

[Table 2 around here]

\section{Experimental results}

We divide this section in three subsections. In Section 4.1 we analyze contributions to the public good in the PUN game. We will see that different organizational structures reach different contribution levels, being contribution increased by punishment in all four networks. Section 4.2 analyzes the different punishment patterns (prosocial, antisocial), and their effect on contributions and punishment in future rounds (retaliation). Section 4.3 compares efficiency across the four networks.

\subsection{Contributions and public good provision}

Figure 2 presents the evolution of contributions to the public good over time in all four networks, in the VCM and in the PUN game. This figure is consistent with the behavioral regularities observed in previous studies. Whereas in the first twenty periods of the VCM game contributions drop over time to very low levels, they immediately jump up at the beginning of the PUN game with no decline over time. After the surprise restart, contribution levels go back to roughly the same level observed in the same network in the first period of the VCM (around 50\% of the endowment).

[Figure 2 around here]

In the PUN game, we observe two very different patterns of contributions across the four networks. In the complete and the star networks, contribution to the public good levels start around $60 \%$ of the endowment and grow to $85 \%$ and $75 \%$, respectively in the last five rounds. In the circle and line networks, contributions to the public good start marginally below the ones observed in the other networks, but follow a flatter path, hardly increasing from $45 \%$ to $52 \%$ of the endowment. 
[Table 3 around here]

Table 3 shows the absolute average contribution in the VCM and PUN games in the first round. In line with Figure 2, differences across networks and types in the first period of both games are never significant and at best marginal. Subjects seem to perceive both games as similar when they first face them. ${ }^{18}$ In the PUN game, contributions in the first round are between $45.6 \%$ (CI) and $60.8 \%$ (ST) of the endowment. Mann-Whitney tests confirm that these differences are only marginally significant between the star network and the other incomplete networks (line and circle), and between the complete network and the circle. ${ }^{19}$ Across degrees, D3 subjects contribute $59.2 \%$ of their endowment in the complete network and $70 \%$ in the star, significantly above the contribution levels of D2 subjects (around 45\% in both the circle and the line). D1 subjects' initial average contribution lays in between (around 55\%), and are not significantly different from the contributions of D2 and D3 subjects using Mann-Whitney tests.

[Table 4 around here]

Table 4 presents a similar analysis to the one in Table 3, showing the absolute average contribution over the whole PUN game, across networks and types, with the average contribution in the VCM game, played by the same subjects, as a benchmark. In all networks, contributions to the public good substantially increase in the PUN game, being the complete network the structure with the highest average contribution (around $77 \%$ of the endowment), and the circle the one with the lowest (51\%). Although punishment opportunities do not have any systematic effect in the first round, they generate a very different dynamics. Using non-parametric tests, contributions are significantly larger in the PUN game than in the VCM game (at the $1 \%$ level taking all networks together, at the $5 \%$ level in the complete, line and star networks one by one, and at the $10 \%$ level in the circle). We summarize these findings in our first result.

Result 1. Across all networks, average contributions to the public good are significantly larger in the PUN game than in the VCM game.

Tables 3 and 4 are also informative about how contribution levels vary across types in the PUN game. We take now our analysis further given that, on the one hand, we have a panel of subjects that interact in fixed groups and, on the other hand, contributions lie in the interval between 0 and 50). In the next tables we report the results of panel data Tobit models with random effects at the individual level. In Table 5 below, we start by documenting treatment differences.

\footnotetext{
18 The only exception is the comparison of D3 types in the star network. In the first period of the PUN game, participants contribute more, even when the difference is only marginally significant (Wilcoxon signed rank test p-value equal to 0.062 ).

${ }^{19}$ In the VCM game, the difference between the line and the star in the first round was also marginally significant.
} 
[Table 5 around here]

Model 1 includes a time variable (Period) and three treatment dummies, one for each incomplete network (being the complete network our benchmark). We also compare the coefficients of the treatment dummies using a t-test, which computes point estimates, standard errors, and p-values for linear combinations of the independent variables (in this case, networks). In line with other experiments on punishment in public goods games (and as observed in Figure 1), model 1 confirms that contribution levels rise over time in our experiment, as the significant and positive coefficient of the variable period documents. We also observe that the complete network and the star outperform the line and the circle (marginally in the comparison between the star and the circle and line), but we do not observe any significant difference between these two networks. This result is consistent with the lack of any monotonic relationship between the number of links in one network, and the contribution levels. While fewer links in the circle and line could be consistent with lower contribution levels in the PUN game (because of fewer punishment opportunities), a hierarchical network with a commonly observed player (like the star network) compensates for the fewer number of links: while the star has the same number of links as the line (3), it achieves the same public good provision as the complete network. As Figure 2 strongly suggests the existence of an end-game effect, in model 2 of Table 5 we add a dummy $(P 20)$ as an explanatory variable, taking the value of 1 if the observation comes from the last period, 0 otherwise. Not surprisingly, $P 20$ is negative and highly significant, but model 2 shows that our results are robust to the introduction of the end-game effect. We summarize these findings in our second result.

Result 2. In the PUN game, the star network outperforms the other incomplete networks (circle and line) in terms of contributions. Contributions to the public good are not significantly lower in the star network than in the complete network.

Our second result illustrates Capenter's (2007) observation that 'hindrances to monitoring do reduce the provision of the public good'. Result 2 strongly suggests that this may be due to the symmetric configurations Carpenter (2007) analyses. While in some asymmetric incomplete networks (like the line), Carpenter's conjecture holds, in hierarchical asymmetric networks (like the star) the same 'hindrance of monitoring' (with respect to the complete network) does not have a negative effect on contributions. In the following section, we study the punishment patterns of each player's type (degree) in each network and their effect on subsequent contributions.

\subsection{Behavioral determinants of punishment}

Table 6 below shows the absolute average number of punishment points, total and per link, sent across networks and degrees. Punishment is remarkably lower in the star network (0.75 
punishment points, half as much as in the other three networks), mainly due to the very low number of punishment points sent by peripheral players: in the star network, punishment is mostly used by central players. In "per link" terms, punishment is the lowest in the complete and star networks, and the highest in the line.

[Table 6 around here]

The comparison relative to the level of punishment exerted in different networks is summarized in the next result.

Result 3. Punishment in the star network is mostly used by the central player. In per link terms, punishment is lower in the complete network and the star.

Punishment has two very different consequences: while it may enhance provision of the public good (team production) tomorrow, it is costly to implement today. Subjects may choose to punish for a variety of reasons, but they need to carefully analyze the trade-off between what they pay today, and what they get in the future. Table 7 below studies why different punishers punish, and Table 8 how punished participants react to punishment in different networks.

Table 7 presents the results of random-effects panel Tobit regressions for punishment, as exerted by different types of subjects. The dependent variable is always the number of punishment points sent by a subject to each of her neighbors. We label the Target as the neighbor receiving the punishment points, being the punishment sent by each subject to each neighbor an observation. In these models, we distinguish three classes (motives) of punishment: pro-social punishment, anti-social punishment and retaliation. Punishment is pro-social (anti-social) when the target contributed less (more) than the punisher. Retaliation happens when agents punish in response to punishment points received in the previous round. ${ }^{20}$

Explanatory variables in Table 7 are: Period, treatment dummies ( $L I$ and $S T$ ), AboveTarget (the excess of contribution of the punisher with respect to the target, 0 if the target contributes more, a measure of pro-social punishment), BelowTarget (the excess of contribution of the target with respect to the punisher, 0 if the target contributes less, a measure of anti-social punishment), and LRecPun (the sanctioning points received in the previous round, a measure of retaliation). In the regressions we include interaction terms to identify treatment specific effects.

[Table 7 around here]

Table 7 provides an explanation of why the star network outperforms the other incomplete networks (and anticipates the information contained in Table 8 below). Not surprisingly, all

\footnotetext{
${ }^{20}$ Although we do not have a counter-punishment stage, retaliation is possible in fixed groups.
} 
participants (D1, D2, D3) punish other participants when contributing less than them (see the positive and significant coefficients for CO*AboveTarget, $C I^{*}$ AboveTarget, LI*AboveTarget and $S T^{*}$ AboveTarget). However, D3 subjects (in the star and complete networks) are the ones choosing not to punish those contributing more than them (see the insignificant coefficients of $S T^{*}$ BelowTarget and $C O^{*}$ BelowTarget), and D3 participants in the star network are the only ones who do not retaliate, when punished (the coefficient for $S T^{*} L R e c P u n$ is not significantly different from zero).

Taken together, these results suggest that the punishment pattern of central players in the star network enhances cooperation because they punish for the right motive (when the contribution of targets is low) and, in sharp contrast with the other networks, central players do not retaliate. In the star network, the 'hindrance of monitoring' is compensated by the pro-social punishing behavior of central players, whereas in the other two incomplete networks (circle and line) retaliation (already present in the complete network) and anti-social punishment prevents D2 participants from generating the same positive response. Interestingly, Table 7 is also informative in other respect: peripheral (D1) participants in the star network punish significantly less than in the line. ${ }^{21}$ We summarize these findings in the following result.

Result 4. Central players in the star network do not punish in an anti-social way (when the target is contributing more than them), and do not condition their level of punishment to previous levels of punishment points received from other participants. In both the circle and the line network central players (D2) punish socially and anti-socially, and retaliate when punished.

We now study the behavioral reaction to punishment, studying whether contributions increase/decrease in reaction to the punishment points sent (and the contributions made) by other group members. Table 8 below presents the results of random-effects panel Tobit regressions in which contribution adjustment (the variations on contributions with respect to the previous period) is the dependent variable. As in the previous models, we report separate regressions for each type of players (regressions 6, 7 and 8, for D1, D2 and D3 subjects, respectively), and the explanatory variables are Period, the two treatment dummies (LI and ST), LDifAbove (the excess of a subject's contribution in the previous period with respect to the average contribution of her neighbors, 0 if the contribution was lower), LDifBelow (the excess of the average contribution of the neighbors in the previous period with respect to the subject's contribution, 0 if higher), and

\footnotetext{
21 As we shall see in Table 8, this is positive for the efficiency of the star network, since D3 subjects do not react to punishment but to observed contributions of D1 participants.
} 
LRecPun (the sanctioning points received in the previous round). ${ }^{22}$ As in Table 7, we also include interaction terms to differentiate network specific effects.

[Table 8 around here]

Period is not significant in any regressions, strongly suggesting that contribution adjustment does not follow a specific time path. The coefficients of $C O^{*} L D i f A b o v e$ (in model 8), $C I^{*}$ LDifAbove (in model 7), LI*LDifAbove (in models 6 and 7) and $S T^{*}$ LDifAbove (in models 7 and 8) are negative and significant, suggesting that contribution adjusts down (decreases) when participants see they are contributing more than their neighbours in all networks. The coefficients of CO*LDifBelow (in model 8), CI*LDifBelow (in model 7), LI*LDifBelow (in models 6 and 7) and $S T^{*}$ LDifBelow (in models 7 and 8 ) are positive and significant, suggesting that subjects also respond as conditional cooperators when they contribute less than the others, increasing their contributions from what they did in the previous round.

Table 8 complements Table 7 in rationalizing the superior performance of the star nertwork: D1 players in the star network (peripheral players) are the only ones significantly and positively reacting to punishment, since they increase their contributions as a reaction (as shown by the positive and significant coefficient of $S T^{*}$ LRecPun in model 6). ${ }^{23}$ We already learned from Table 7 that D3 players in the star network punish for the right reason (pro-social punishment), now in Table 8 we see that this behavior increases contributions to the public good because D3 players are able to generate a positive response in D1 subjects only in the star network. D3 players in the star network are the only ones with stronger upward reactions (when below the average) than downward adjustments (when above the others). ${ }^{24}$ D3 players in hierarchical networks (like the star network) promote cooperation and D1 participants in these hierarchical environments positively respond back. We summarize these findings in the following result.

Result 5. All types of players in all networks act as conditional cooperators. Peripheral players (D1) in the star network are the only ones significantly and positively reacting to punishment, adjusting their contributions up.

\subsection{Efficiency}

As we argued, punishment is a mechanism with two sides: if successful, it may enhance public good provision at a substantial individual cost. The net welfare effect of punishment,

\footnotetext{
22 Note that for D1 players the average corresponds to the only contribution they observe.

${ }^{23}$ Note that other types in other networks only (significantly) adjust their contributions in response to the observed contributions of others.

24 This result is consistent with previous results on peer comparisons and social norms. Alcott and Rogers (2014) show a behaviourally inspired public intervention in which millions of US households were repeatedly mailed personalized social comparison-based home energy reports, with a positive effect in the long-run (treatment effects are strong after two years).
} 
balancing the gains (provision) and losses (cost) of punishment can only be empirically assessed. In this section, we study a basic and meaningful measure of efficiency (earnings) across treatments and types.

[Table 9 around here]

Table 9 above descriptively presents the average profits across networks and degrees in the VCM and PUN games. In both games, the complete and star networks exhibit very similar profit levels (73.64 and 73.88 in the VCM, and 73.65 and 76.57 in PUN). Average profits are also quite close in the circle and line networks (68.9 and 66.05 in VCM, and 62.03 and 61.41 in PUN). Again, the star network slightly outperforms the other two incomplete networks, and differences increase in the PUN game. Earnings are distributed among types of players in a very illustrative way: central (D3) players in the star network make substantially less (67.06) than peripheral (D1) ones (79.74). This difference is consistent with the substantial costs assumed by central players in the star network. ${ }^{25}$

Table 10 presents simple random-effects panel regressions for treatment effects in earnings made by subjects, including a period variable and treatment dummies. Table 10 show that efficiency (earnings) is higher in both the complete and the star network when compared to the circle and the line. Star and complete networks show no significant differences.

[Table 10 around here]

Figure 3 complements these results by plotting (normalized) kernel density functions for group profits in the four treatments of the PUN game. In line with Table 10, the density functions of the star and the complete networks are shifted to the right with respect to those for the circle and the line.

[Figure 3 around here]

Finally, Figure 4 shows (normalized) kernel density functions for the VCM game and the PUN game, strongly suggesting that while in the circle and line networks, the introduction of punishment opportunities results in efficiency losses, in the star and complete networks efficiency gains are common in a substantial fraction of individuals and groups, especially in the star. ${ }^{26}$

[Figure 4 around here]

\footnotetext{
${ }^{25}$ This result is reminiscent of the role of payoff inequality in the so-called 'center sponsored star' in the network formation literature (see Bala and Goyal, 2000, for theory and Falk and Kosfeld, 2012, for experimental evidence).

${ }^{26}$ For the (baseline) complete network, by running experiments for 50 rounds, Gächter et al (2008) show that punishment makes groups and individuals better off in the long run (the costs of punishment become negligible and are outweighed by the increased gains from cooperation). Thus, the efficiency gains seem to materialize over time if there is a large enough time horizon.
} 
These observations lead to our final result.

Result 6. Efficiency (earnings) in the star network is significantly higher than in the other incomplete networks. Efficiency levels in the star and complete networks are not significantly different.

\section{Conclusion}

In many real-world situations individuals interact under informal institutions. These institutions are internally structured and many times adopt a hierarchical form, with coordinators (central players) monitoring other individuals (peripheral players), typically at a personal cost, with the potential, or maybe the goal, of fostering efficiency.

Organizations aiming to maximize team production is one example. Cycling competitions is another good one. In mountain stages, riders with poor climbing skills stay together and form a group, informally called gruppeto, with the aim to reach simultaneously the end of race, hopefully not out of time. As a populated group, officials may let them stay in the race if they don't finish in time (the argument being that many riders would otherwise be eliminated). To follow the (slow) pace of the grupetto is a public good: Each cyclist would like to go faster than his peers to achieve a better time, but he enjoys from others not riding too fast because, if his forces eventually fail, he can join the grupetto, reducing the risk of being eliminated (the larger the grupetto, the lower the risk). The interesting point to our case is that quite often, the gruppeto experiences the emergence of a leader, who takes the responsibility of maintaining the cohesion of the group, including tasks such as yelling at those cyclists that ride faster than others in the group. As an example of a social dilemma in which a hierarchical network with a central coordinator endogenously emerges, the "leader" incurs the cost of monitoring others, but his behavior is what allows the "public good" to be (efficiently) provided. ${ }^{27}$

Our results have also relevant implications in other contexts which can be modelled as a public good, like international cooperation against terrorism. Countries may invest resources actively fighting international terrorism, and at the same time providing benefits to others. As Enders and Sandler (2006, p. 159) argue, "Although difficult to achieve, international cooperation will not only conserve resources but also make for more effective resource allocation. If international cooperation is to work, then an enforcement mechanism is needed, and that is unlikely at this time /... / Unless nations universally view the benefits of such arrangements as sufficient to support their efforts, noncompliant nations can be the spoilers by offsetting cooperative gains". In line with Arce et al (2011) and Kass et al (2015), our results suggest that

\footnotetext{
27 Other examples of networks that frequently adopt a hierarchical structure are criminal networks (see Baccara and Bar-Isaac, 2008; and Mastrobuoni and Patacchini, 2012), and also institutions that aim to maintain order by achieving collective effort like, e.g., the military or police.
} 
if such a (potential) mechanism involves a centralized institution sanctioning countries that do not cooperate, it might be effective.

In summary, participants in our experiment, randomly allocated to different positions in different networks, follow very different punishment patterns in an identical social dilemma, triggering very different behavioral reactions in their counterparts. In isolation from any selection effect, the very same hierarchical nature of the social structure transforms the way central players sanction peripheral players and respond to the interaction with others. Being at the center of a hierarchical network is a behavioral factor we should not dismiss.

\section{References}

Allcot, H. and T. Rogers (2014): "The Short-Run and Long-Run Effects of Behavioral Interventions: Experimental Evidence from Energy Conservation", American Economic Review 104(10), 3003-3037.

Arce, D.G., Bakshi, S., Croson, R.T., Eckel, C.C., Fatas, E., and M. Kass (2011): "Counterterrorism Strategies in the Lab", Public Choice 149(3-4), 465.

Baccara, M. and H. Bar-Isaac (2008): "How to Organize Crime", Review of Economic Studies $75,1039-1067$.

Bala, V. and S. Goyal (2000): “A Noncooperative Model of Network Formation”, Econometrica 68(5), 1181-1229.

Bendahan, S., Zehnder, C., Pralong, F.P., and J. Antonakis (2015): "Leader Corruption Depends on Power and Testosterone", The Leadership Quarterly 26, 101-122.

Baldassarri, D. and G. Grossman (2013): "The Effect of Group Attachment and Social Position on Prosocial Behavior. Evidence from Lab-in-the-field Experiments", Plos One 8(3), e58750.

Berardo, R. and J.T. Scholz (2010): "Self-organizing Policy Networks: Risk, Partner Selection, and Cooperation in Estuaries", American Journal of Political Science 54(3), 632-649.

Bramoullé, Y. and R. Kranton (2007): "Public Goods in Networks", Journal of Economic Theory $135,478-494$.

Calabuig, V., Fatas, E., Olcina, G., and I. Rodriguez-Lara (2016): “Carry a Big Stick, or no Stick at All: Punishment and Endowment Heterogeneity in the Trust Game", Journal of Economic Psychology 57, 153-171.

Carpenter, J.P. (2007): "Punishing Free-riders: How Group Size Affects Mutual Monitoring and the Provision of Public Goods", Games and Economic Behavior 60, 31-55. 
Carpenter, J., Kariv, S., and A. Schotter (2012): "Network Architecture, Cooperation and Punishment in Public Good Experiments", Review of Economic Design 16, 93-118.

Cassar, A. (2007): "Coordination and Cooperation in Local, Random and Small World Networks: Experimental Evidence”, Games and Economic Behavior, 58, 209-230.

Chaudhuri, A. (2011): "Sustaining Cooperation in Laboratory Public Goods Experiments: A Selective Survey of the Literature", Experimental Economics, 14, 47-83.

Charness, G., Feri, F., Meléndez-Jiménez, M.A., and M. Sutter (2014): “Experimental Games on Networks: Underpinnings of Behavior and Equilibrium Selection”, Econometrica 82, 1615-1670.

Cinyabuguma, M., Page, T., and L. Putterman (2006): “Can second-order punishment deter perverse punishment?", Experimental Economics 9, 265-279.

Croson, R., Fatas, E., and T. Neugebauer (2005): "Reciprocity, Matching and Conditional Cooperation in Two Public Goods Games", Economics Letters 87(1), 95-101.

Croson, R., Fatas, E., Neugebauer, T., and A.J. Morales (2015): "Excludability: A Laboratory Study on Forced Ranking in Team Production". Journal of Economic Behavior \& Organization $114,13-26$.

Czaplicka, A., Holyst, J.A., and P.M.A. Sloot (2013): "Noise Enhances Information Transfer in Hierarchical Networks", Scientific Reports 3, 1223.

Eckel, C., Fatas, E., and R. Wilson (2010): "Status and Cooperation in Organizations", Journal of Public Economic Theory 12(4), 737-762.

Eckel, C.C., Fatas, E., Godoy, S., and R.K. Wilson (2016): “Group-Level Selection Increases Cooperation in the Public Goods Game”, PloS ONE 11(8), e0157840.

Eisenegger, C., Naef, M., Snozzi, R., Heinrichs, M., and E. Fehr (2012): “New Evidence on Testosterone and Cooperation: Reply", Nature 485, 7399, p. E5-E6.

Enders, W. and T. Sandler (2006): The Political Economy of Terrorism. Cambridge University Press, New York.

Fatas, E. and G. Mateu (2015): "Antisocial Punishment in Two Social Dilemmas", Frontiers in Behavioral Neuroscience 9, 107.

Fatas, E., Meléndez-Jiménez, M.A., and H. Solaz (2010a): “An Experimental Analysis of Team Production in Networks", Experimental Economics 13, 399-411.

Fatas, E., Morales, A. J., and P. Ubeda (2010b): "Blind Justice: An Experimental Analysis of Random Punishment in Team Production". Journal of Economic Psychology 31(3), 358-373. 
Falk, A. and M. Kosfeld (2012): "It's all about Connections: Evidence on Network Formation". Review of Network economics 11(3), Article 2.

Fehr, E. and S. Gächter (2000): "Cooperation and Punishment in Public Goods Experiments", American Economic Review 90, 980-994.

Fehr, E. and S. Gächter (2002): “Altruistic Punishment in Humans”, Nature 415, 137-140.

Fushing, H., McAssey, M.P., Beisner, B., and B. McCowan (2011): “Ranking network of a captive rhesus macaque society: A sophisticated corporative kingdom", PLOS ONE 6(3), e17817.

Fischbacher, U. (2007): “z-Tree: Zurich Toolbox for Ready-made Economic Experiments", Experimental Economics 10 (2), 171-178.

Gächter, S. and B. Herrmann (2009): "Reciprocity, Culture and Human Cooperation: Previous Insights and a New Cross-cultural Experiment", Philosophical Transactions of the Royal Society B 364, 791-806.

Gächter, S., Renner, E., and M. Sefton (2008): “The Long-Run Benefits of Punishment”, Science $322,1510-1510$.

Grossman, G. (2104): "Do Selection Rules Affect Leader Responsiveness? Evidence from Rural Uganda", Quarterly Journal of Political Science, 9(1), 1-44.

Grossman, G. and D. Baldassarri (2012): "The Impact of Elections on Cooperation: Evidence from a Lab-in-the-field Experiment in Uganda", American Journal of Political Science 56(4), 964-985.

Habyarimana, J., Humphreys, M., Posner, D.N., and J.N. Weinstein (2007): “Why Does Ethnic Diversity Undermine Public Goods Provision?", American Political Science Review 101(4), 709725 .

Hardy, C.L. and M. Van Vugt (2006): "Nice Guys Finish First: The Competitive Altruism Hypothesis", Personality and Social Psychology Bulletin 32, 1402-1413.

Harrel, A. and B. Simpson (2016): "The Dynamics of Prosocial Leadership: Power and Influence in Collective Action Groups", Social Forces 94(3), 1283-1308.

Herrmann, B., Thöni, C., and S. Gächter (2008): “Antisocial Punishment across Societies”, Science 319, 1362-1367.

Jack, B.K. and M.P. Recalde (2015): "Leadership and the Voluntary Provision of Public Goods: Field Evidence from Bolivia", Journal of Public Economics 122, 80-93.

Kaiser, M. and C.C. Hilgetag (2010): "Optimal hierarchical modular topologies for producing limited sustained activation of neural networks", Frontiers in Neuroinformatics 4, 8 . 
Kass, M., Fatas, E., Eckel, C.C., and D. Arce (2015): "The UN in the Lab", Social Choice and Welfare, 45(3), 625-651.

Kirchkamp, O. and R. Nagel (2007): "Naive Learning and Cooperation in Network Experiments", Games and Economic Behavior 58, 269-292.

Kosfeld, M. and D. Rustagi (2015): "Leader Punishment and Cooperation in Groups: Experimental Field Evidence from Commons Management in Ethiopia", American Economic Review 105(2), 747-783.

Leibbrandt, A., Ramalingam, A., Sääksvuori, L., and J.M. Walker (2015): "Incomplete Punishment Networks in Public Good Games: Experimental Evidence”, Experimental Economics $18,15-37$.

Lierl, M. (2016): "Social Sanctions and Informal Accountability: Evidence from a Laboratory Experiment". Journal of Theoretical Politics 28(1), 74-104.

Ma, H.W., Buer, J., and A.P. Zeng (2004): "Hierarchical Structure and Modules in the Escherichia Coli Transcriptional Regulatory Network Revealed by a New Top-Down Approach", BMC Bioinformatics 5:199.

Magee, J.C. and A.D. Galinsky (2008): "Social Hierarchy: The Self-Reinforcing Nature of Power and Status", The Academy of Management Annals 2(1), 351-398.

Mastrobuoni, G. and E. Patacchini (2012): “Organized Crime Networks: an Application of Network Analysis Techniques to the American Mafia", Review of Network Economics 11(3), Art. 10.

Mones, E. (2013): “Hierarchy in Directed Random Networks”, Physical Review E 87, 022817.

Nagy, M., Akos, Z., Biro, B., and T. Vicsek (2010): "Hierarchical Group Dynamics in Pigeon Flocks", Nature 464(8), 890-893.

Nikiforiakis, N. (2008): "Punishment and Counter-Punishment in Public Good Games: Can we Really Govern Ourselves?", Journal of Public Economics 92, 91-112.

O’Gorman, R., Henrich, J., and M. Van Vugt (2009): “Constraining Free-Riding in Public Good Games: Designated Solitary Punishers can Sustain Human Cooperation", Proceedings of the Royal Society B 276, 323-329.

Ostrom, E., Walker, J., and R. Gardner (1992): "Covenants with and without a Sword: SelfGovernance is Possible", American Political Science Review 86(2), 404-417.

Ravasz, E. and A.-L. Barabási (2003): "Hierarchical Organization in Complex Networks", Physical Review E 67, 026112. 
Rosenkranz, S. and U. Weitzel (2012): "Network Structure and Strategic Investments: An Experimental Analysis", Games and Economic Behavior 75, 898-920.

Siegel D.A. (2009): "Social Networks and Collective Action", American Journal of Political Science 53(1), 122-138.

Sutter, M., Haigner, S., and M.G. Kocher (2010): “Choosing the Carrot or the Stick? Endogenous Institutional Choice in Social Dilemma Situations", Review of Economic Studies 77(4), 15401566.

Swai, H. (2013): "Structuring Hierarchical Multi-Star Small-World Networks for Real-World Applications", Procedia Computer Science 18, 2410-2419.

Tsai, L.L. (2007): “Solidary Groups, Informal Accountability, and Local Public Goods Provision in Rural China", American Political Science Review 101(2), 355-372.

Wang, L.-N., Guo, J.-L., Yang, H.-X., and T. Zhou (2009): “Local Preferential Attachment Model for Hierarchical Networks", Physica A 388(8), 1713-1720.

Willer, R. (2009): "Groups Reward Individual Sacrifice: The Status Solution to the Collective Action Problem", American Sociological Review 74, $23-43$.

Yamagishi, T. (1986): "The Provision of a Sanctioning System as a Public Good", Journal of Personality and social Psychology 51(1), 110. 


\section{Tables and figures}

Figure 1: Networks

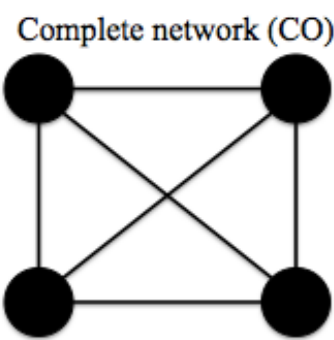

Line (LI)

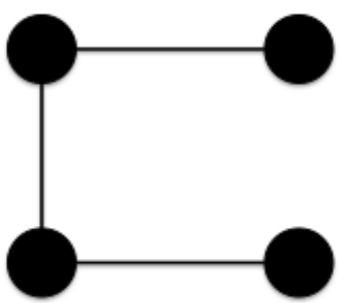

Circle (CI)

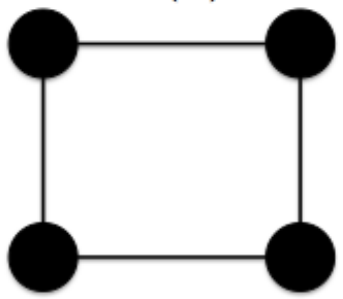

Star network (ST)

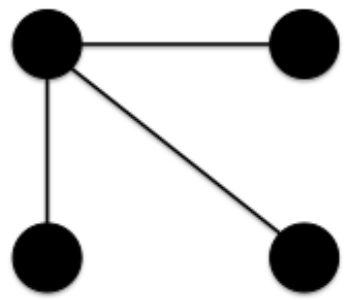


Table 1: Punishment cost

\begin{tabular}{cccccccccccc} 
Punishment points $P_{\text {in }}$ & 0 & 1 & 2 & 3 & 4 & 5 & 6 & 7 & 8 & 9 & 10 \\
Cost of Punishment $K\left(P_{\text {in }}\right)$ & 0 & 2 & 4 & 8 & 12 & 18 & 24 & 32 & 40 & 50 & 60 \\
\hline
\end{tabular}


Table 2: Summary of treatments and sessions

\begin{tabular}{ccccc}
\hline \hline & \multirow{2}{*}{ Network } & \# Subjects & \multicolumn{2}{c}{ Game } \\
\cline { 4 - 5 } 1 & Complete & 36 & Veriod 1 - 20 & Period 21 - 40 \\
\hline 2 & Circle & 36 & VCM & PUN \\
3 & Line & 40 & VCM & PUN \\
4 & Star & 32 & VCM & PUN \\
\hline
\end{tabular}


Figure 2: Evolution of contributions

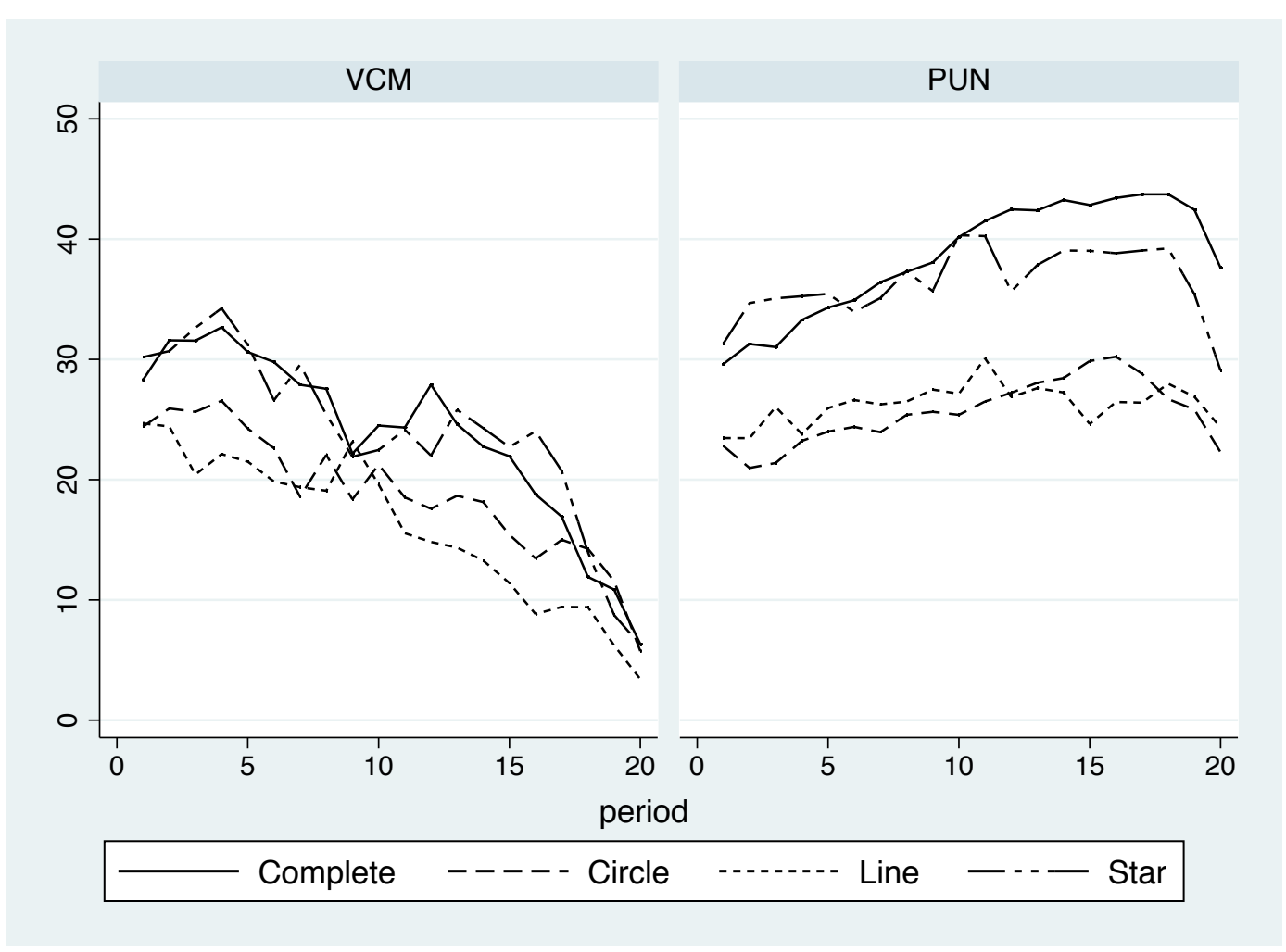


Table 3: Average contribution - First period

\begin{tabular}{|c|c|c|c|c|c|c|c|}
\hline \multicolumn{2}{|c|}{ Contribution } & \multirow{2}{*}{$\begin{array}{c}\text { All Degrees } \\
26.743 \\
(15.609)\end{array}$} & \multirow{2}{*}{$\begin{array}{c}\text { D1 } \\
27.114 \\
(15.243)\end{array}$} & \multirow{2}{*}{$\begin{array}{c}\text { D2 } \\
24.982 \\
(17.395)\end{array}$} & \multirow{2}{*}{$\begin{array}{c}\text { D3 } \\
28.614 \\
(13.534)\end{array}$} & \multicolumn{2}{|c|}{ Mann-Whitney p-values } \\
\hline \multirow{5}{*}{$\begin{array}{c}\text { First } \\
\text { Period } \\
\text { VCM }\end{array}$} & All Networks & & & & & $\begin{array}{c}\text { CO vs. CI } \\
0.408\end{array}$ & $\begin{array}{c}\text { CO vs. LI } \\
0.287\end{array}$ \\
\hline & $\begin{array}{c}\text { Complete } \\
\text { network (CO) }\end{array}$ & $\begin{array}{c}28.306 \\
(14.150)\end{array}$ & & & $\begin{array}{c}28.306 \\
(14.150)\end{array}$ & $\begin{array}{c}\text { CO vs. ST } \\
0.498\end{array}$ & $\begin{array}{l}\text { CI vs. LI } \\
0.992\end{array}$ \\
\hline & Circle (CI) & $\begin{array}{c}24.417 \\
(17.793)\end{array}$ & & $\begin{array}{c}24.417 \\
(17.793)\end{array}$ & & $\begin{array}{c}\text { CI vs. ST } \\
0.148\end{array}$ & $\begin{array}{c}\text { LI vs. ST } \\
0.093\end{array}$ \\
\hline & Line (LI) & $\begin{array}{c}24.675 \\
(16.112)\end{array}$ & $\begin{array}{c}23.35 \\
(15.432)\end{array}$ & $\begin{array}{c}26 \\
(17.060)\end{array}$ & & $\begin{array}{c}\text { D1 vs. D2 } \\
0.445\end{array}$ & $\begin{array}{c}\text { D1 vs. D3 } \\
0.739\end{array}$ \\
\hline & Star (ST) & $\begin{array}{c}30.188 \\
(13.674)\end{array}$ & $\begin{array}{c}30.25 \\
(14.665)\end{array}$ & & $\begin{array}{c}30 \\
(11.019)\end{array}$ & $\begin{array}{c}\text { D2 vs. D3 } \\
0.252\end{array}$ & \\
\hline \multirow{5}{*}{$\begin{array}{l}\text { First } \\
\text { Period } \\
\text { PUN }\end{array}$} & All Networks & $\begin{array}{c}26.444 \\
(16.848)\end{array}$ & $\begin{array}{c}27.068 \\
(16.483)\end{array}$ & $\begin{array}{c}22.693 \\
(17.913)\end{array}$ & $\begin{array}{l}30.591 \\
(15.02)\end{array}$ & $\begin{array}{c}\text { CO vs. CI } \\
0.081\end{array}$ & $\begin{array}{c}\text { CO vs. LI } \\
0.124\end{array}$ \\
\hline & $\begin{array}{c}\text { Complete } \\
\text { network }(\mathrm{CO})\end{array}$ & $\begin{array}{c}29.611 \\
(15.639)\end{array}$ & & & $\begin{array}{c}29.611 \\
(15.639)\end{array}$ & $\begin{array}{c}\mathrm{CO} \text { vs. } \mathrm{ST} \\
0.8\end{array}$ & $\begin{array}{c}\text { CI vs. LI } \\
0.773\end{array}$ \\
\hline & Circle (CI) & $\begin{array}{c}22.805 \\
(17.946)\end{array}$ & & $\begin{array}{c}22.805 \\
(17.946)\end{array}$ & & $\begin{array}{c}\text { CI vs. ST } \\
0.069\end{array}$ & $\begin{array}{c}\text { LI vs. ST } \\
0.086\end{array}$ \\
\hline & Line (LI) & $\begin{array}{c}23.7 \\
(17.517)\end{array}$ & $\begin{array}{c}24.9 \\
(17.066)\end{array}$ & $\begin{array}{c}22.5 \\
(18.317)\end{array}$ & & $\begin{array}{c}\text { D1 vs. D2 } \\
0.167\end{array}$ & $\begin{array}{c}\text { D1 vs. D3 } \\
0.335\end{array}$ \\
\hline & Star (ST) & $\begin{array}{c}30.406 \\
(15.189)\end{array}$ & $\begin{array}{l}28.875 \\
(16.12)\end{array}$ & & $\begin{array}{c}35^{*} \\
(11.65)\end{array}$ & $\begin{array}{c}\text { D2 vs. D3 } \\
0.019\end{array}$ & \\
\hline
\end{tabular}

Standard deviation between brackets.

PUN vs. VCM: Wilcoxon Signed ranks test significance at $* * * \mathrm{p}<0.01, * * \mathrm{p}<0.05,{ }^{*} \mathrm{p}<0.1$ 
Table 4: Average contribution - All periods

\begin{tabular}{|c|c|c|c|c|c|}
\hline \multicolumn{2}{|c|}{ Contribution } & All Degrees & D1 & D2 & D3 \\
\hline \multirow{5}{*}{$\begin{array}{l}\text { All Periods } \\
\text { VCM }\end{array}$} & All Networks & $\begin{array}{c}20.401 \\
(17.693)\end{array}$ & $\begin{array}{c}20.270 \\
(17.413)\end{array}$ & $\begin{array}{c}17.707 \\
(17.841)\end{array}$ & $\begin{array}{c}23.959 \\
(17.174)\end{array}$ \\
\hline & $\begin{array}{l}\text { Complete } \\
\text { network }\end{array}$ & $\begin{array}{c}23.647 \\
(16.953)\end{array}$ & & & $\begin{array}{c}23.647 \\
(16.953)\end{array}$ \\
\hline & Circle & $\begin{array}{c}18.9 \\
(18.184)\end{array}$ & & $\begin{array}{c}18.9 \\
(18.184)\end{array}$ & \\
\hline & Line & $\begin{array}{c}16.046 \\
(16.974)\end{array}$ & $\begin{array}{c}16.532 \\
(16.937)\end{array}$ & $\begin{array}{c}15.56 \\
(17.018)\end{array}$ & \\
\hline & Star & $\begin{array}{c}23.879 \\
(17.447)\end{array}$ & $\begin{array}{c}23.385 \\
(17.207)\end{array}$ & & $\begin{array}{c}25.362 \\
(18.123)\end{array}$ \\
\hline \multirow{5}{*}{$\begin{array}{l}\text { All Periods } \\
\text { PUN }\end{array}$} & All Networks & $\begin{array}{c}31.202^{* * *} \\
(18.115)\end{array}$ & $\begin{array}{c}30.314 * * \\
(18.244)\end{array}$ & $\begin{array}{c}26.19 * * * \\
(19.101)\end{array}$ & $\begin{array}{c}38.468 * * * \\
(13.85)\end{array}$ \\
\hline & $\begin{array}{l}\text { Complete } \\
\text { network }\end{array}$ & $\begin{array}{c}38.485^{* *} \\
(13.833)\end{array}$ & & & $\begin{array}{c}38.485^{* *} \\
(13.833)\end{array}$ \\
\hline & Circle & $\begin{array}{l}25.553^{*} \\
(18.655)\end{array}$ & & $\begin{array}{l}25.553^{*} \\
(18.655)\end{array}$ & \\
\hline & Line & $\begin{array}{c}25.991 * * \\
(19.766)\end{array}$ & $\begin{array}{c}24.645 \\
(19.614)\end{array}$ & $\begin{array}{c}27.337 * * \\
(19.85)\end{array}$ & \\
\hline & Star & $\begin{array}{c}35.877 * * \\
(15.212)\end{array}$ & $\begin{array}{c}35.037 * * \\
(15.528)\end{array}$ & & $\begin{array}{c}38.394 * * \\
(13.968)\end{array}$ \\
\hline
\end{tabular}

Standard deviation between brackets.

PUN vs. VCM: Wilcoxon Signed ranks test significance at ${ }^{* * *} \mathrm{p}<0.01,{ }^{* *} \mathrm{p}<0.05,{ }^{*} \mathrm{p}<0.1$ 
Table 5: Determinants of contributions

\begin{tabular}{ccc} 
& $(1)$ & $(2)$ \\
\hline \multirow{2}{*}{ Intercept } & $43.960^{* * *}$ & $42.694^{* * *}$ \\
& $(4.134)$ & $(4.141)$ \\
Period & $0.540^{* * *}$ & $0.725^{* * *}$ \\
& $(0.053)$ & $(0.056)$ \\
CI & $-20.299^{* * *}$ & $-20.311^{* * *}$ \\
& $(5.762)$ & $(5.772)$ \\
LI & $-20.005^{* * *}$ & $-19.953^{* * *}$ \\
& $(5.624)$ & $(5.634)$ \\
ST & -9.069 & -9.098 \\
& $(5.930)$ & $(5.940)$ \\
P20 & & $-12.767 * * *$ \\
& & $(1.471)$ \\
\hline \multirow{2}{*}{ CI - LI } & -0.294 & -0.358 \\
& $(5.589)$ & $(5.599)$ \\
CI - ST & $-11.230^{*}$ & $-11.213^{*}$ \\
& $(5.897)$ & $(5.907)$ \\
LI - ST & $-10.936^{*}$ & $-10.855^{*}$ \\
\#Obs & $(5.762)$ & $(5.772)$ \\
\hline Log likelihood & 2880 & 2880 \\
Prob > chi2 & 0.0000 & -7578.3913 \\
\end{tabular}


Table 6: Punishment points sent across networks and types

\begin{tabular}{|c|c|c|c|c|c|}
\hline \multicolumn{2}{|c|}{ Punishment } & All Degrees & D1 & $\mathrm{D} 2$ & D3 \\
\hline \multirow{5}{*}{ Total } & $\begin{array}{c}\text { All } \\
\text { Networks }\end{array}$ & $\begin{array}{l}1.168 \\
(2.200)\end{array}$ & $\begin{array}{c}0.749 \\
(1.502)\end{array}$ & $\begin{array}{c}1.345 \\
(2.144)\end{array}$ & $\begin{array}{c}1.361 \\
(2.738)\end{array}$ \\
\hline & $\begin{array}{c}\text { Complete } \\
\text { net. }\end{array}$ & $\begin{array}{l}1.271 \\
(2.741)\end{array}$ & & \multirow{4}{*}{$\begin{array}{c}1.249 \\
(2.124) \\
1.517 \\
(2.172)\end{array}$} & $\begin{array}{c}1.271 \\
(2.741)\end{array}$ \\
\hline & Circle & $\begin{array}{c}1.249 \\
(2.124)\end{array}$ & & & \\
\hline & Line & $\begin{array}{c}1.336 \\
(1.988)\end{array}$ & $\begin{array}{c}1.155 \\
(1.769)\end{array}$ & & \\
\hline & Star & $\begin{array}{c}0.750 \\
(1.766)\end{array}$ & $\begin{array}{c}0.410 \\
(1.132)\end{array}$ & & $\begin{array}{c}1.769 \\
(2.697) \\
\end{array}$ \\
\hline \multirow{5}{*}{ Per link } & $\begin{array}{c}\text { All } \\
\text { Networks }\end{array}$ & $\begin{array}{c}0.584 \\
(1.333)\end{array}$ & $\begin{array}{c}0.749 \\
(1.502)\end{array}$ & $\begin{array}{c}0.672 \\
(1.388)\end{array}$ & $\begin{array}{c}0.454 \\
(1.208)\end{array}$ \\
\hline & $\begin{array}{c}\text { Complete } \\
\text { net. }\end{array}$ & $\begin{array}{c}0.424 \\
(1.105)\end{array}$ & & \multirow{4}{*}{$\begin{array}{c}0.624 \\
(1.334) \\
0.759 \\
(1.476)\end{array}$} & $\begin{array}{c}0.424 \\
(1.105)\end{array}$ \\
\hline & Circle & $\begin{array}{c}0.624 \\
(1.334)\end{array}$ & & & \\
\hline & Line & $\begin{array}{c}0.891 \\
(1.590)\end{array}$ & $\begin{array}{c}1.155 \\
(1.769)\end{array}$ & & \\
\hline & Star & $\begin{array}{c}0.500 \\
(1.380)\end{array}$ & $\begin{array}{c}0.410 \\
(1.132)\end{array}$ & & $\begin{array}{c}0.590 \\
(1.585)\end{array}$ \\
\hline
\end{tabular}

Standard deviation between brackets. 
Table 7: Determinants of punishment

\begin{tabular}{|c|c|c|c|}
\hline & (3) & $\begin{array}{l}\text { (4) } \\
\text { D2 }\end{array}$ & (5) \\
\hline Intercept & $-2.705 * * *$ & $-2.893 * * *$ & $-3.075 * * *$ \\
\hline Period & $\begin{array}{c}0.068^{* * * *} \\
(0.021)\end{array}$ & $\begin{array}{l}-0.019 \\
(0.013)\end{array}$ & $\begin{array}{c}-0.058 * * * \\
(0.014)\end{array}$ \\
\hline LI & & $\begin{array}{c}0.420 \\
(0.523)\end{array}$ & \\
\hline ST & $\begin{array}{c}-1.879 * * \\
(0.755)\end{array}$ & & $\begin{array}{c}0.221 \\
(0.889)\end{array}$ \\
\hline $\mathrm{CO} *$ AboveTarget & & & $\begin{array}{c}0.190 * * * \\
(0.011)\end{array}$ \\
\hline CI * AboveTarget & & $\begin{array}{c}0.167 * * * \\
(0.012)\end{array}$ & \\
\hline LI * AboveTarget & $\begin{array}{c}0.160 * * * \\
(0.019)\end{array}$ & $\begin{array}{c}0.151 * * * \\
(0.011)\end{array}$ & \\
\hline ST * AboveTarget & $\begin{array}{c}0.149 * * * \\
(0.020)\end{array}$ & & $\begin{array}{c}0.186^{* * * *} \\
(0.015)\end{array}$ \\
\hline CO * BelowTarget & & & $\begin{array}{c}-0.021 \\
(0.017)\end{array}$ \\
\hline CI * BelowTarget & & $\begin{array}{c}0.040 * * * \\
(0.013)\end{array}$ & \\
\hline LI * BelowTarget & $\begin{array}{c}0.076 * * * \\
(0.016)\end{array}$ & $\begin{array}{l}-0.002 \\
(0.015)\end{array}$ & \\
\hline ST * BelowTarget & $\begin{array}{c}0.027 \\
(0.019)\end{array}$ & & $\begin{array}{c}0.002 \\
(0.028)\end{array}$ \\
\hline CO * LRecPun & & & $\begin{array}{c}0.166^{* * *} \\
(0.038)\end{array}$ \\
\hline CI * LRecPun & & $\begin{array}{c}0.271 * * * \\
(0.053)\end{array}$ & \\
\hline LI * LRecPun & $\begin{array}{l}0.181^{*} \\
(0.109)\end{array}$ & $\begin{array}{c}0.149 * * * \\
(0.055)\end{array}$ & \\
\hline ST * LRecPun & $\begin{array}{c}0.258^{* *} \\
(0.118) \\
\end{array}$ & & $\begin{array}{c}0.010 \\
(0.092) \\
\end{array}$ \\
\hline \#Obs & 836 & 2128 & 2508 \\
\hline Log likelihood & -780.01418 & -2023.5733 & -1730.0175 \\
\hline Prob > chi 2 & 0.0000 & 0.0000 & 0.0000 \\
\hline
\end{tabular}


Table 8: Determinants of Increase in contributions

\begin{tabular}{|c|c|c|c|}
\hline & $\begin{array}{l}(6) \\
\text { D1 }\end{array}$ & $\begin{array}{l}\text { (7) } \\
\text { D2 }\end{array}$ & $\begin{array}{l}\text { (8) } \\
\text { D3 }\end{array}$ \\
\hline Intercept & $\begin{array}{c}3.876 \\
(2.688)\end{array}$ & $\begin{array}{c}6.974 * * * \\
(2.192)\end{array}$ & $\begin{array}{c}8.663 * * * \\
(2.059)\end{array}$ \\
\hline Period & $\begin{array}{l}-0.106 \\
(0.090)\end{array}$ & $\begin{array}{l}-0.051 \\
(0.075)\end{array}$ & $\begin{array}{c}0.117 \\
(0.089)\end{array}$ \\
\hline LI & & $\begin{array}{l}-2.043 \\
(3.398)\end{array}$ & \\
\hline ST & $\begin{array}{c}-0.381 \\
(3.311)\end{array}$ & & $\begin{array}{l}-2.447 \\
(4.028)\end{array}$ \\
\hline CO *LDifAbove & & & $\begin{array}{c}-0.827 * * * \\
(0.149)\end{array}$ \\
\hline CI * LDifAbove & & $\begin{array}{c}-0.896 * * * \\
(0.098)\end{array}$ & \\
\hline LI * LDifAbove & $\begin{array}{c}-0.497 * * * \\
(0.104)\end{array}$ & $\begin{array}{c}-0.669 * * * \\
(0.095)\end{array}$ & \\
\hline ST $*$ LDifAbove & $\begin{array}{c}-0.633 * * * \\
(0.094)\end{array}$ & & $\begin{array}{c}-0.469 * * * \\
(0.151)\end{array}$ \\
\hline $\mathrm{CO} *$ LDifbelow & & & $\begin{array}{c}0.659 * * * \\
(0.115)\end{array}$ \\
\hline CI * LDifbelow & & $\begin{array}{c}0.184 * * \\
(0.088)\end{array}$ & \\
\hline LI * LDifbelow & $\begin{array}{l}0.162^{*} \\
(0.091)\end{array}$ & $\begin{array}{c}0.631 * * * \\
(0.122)\end{array}$ & \\
\hline ST* LDifbelow & $\begin{array}{c}0.323^{* * *} * \\
(0.082)\end{array}$ & & $\begin{array}{c}0.614 * * * \\
(0.221)\end{array}$ \\
\hline $\mathrm{CO} *$ LRecPun & & & $\begin{array}{c}-0.517 \\
(0.348)\end{array}$ \\
\hline CI * LRecPun & & $\begin{array}{l}-0.489 \\
(0.330)\end{array}$ & \\
\hline LI * LRecPun & $\begin{array}{c}0.463 \\
(0.626)\end{array}$ & $\begin{array}{c}0.230 \\
(0.401)\end{array}$ & \\
\hline ST * LRecPun & $\begin{array}{c}1.804 * * * \\
(0.646)\end{array}$ & & $\begin{array}{l}-0.145 \\
(0.688)\end{array}$ \\
\hline \#Obs & 836 & 1064 & 836 \\
\hline Log likelihood & -2266.8294 & -2713.6669 & -1718.2564 \\
\hline Prob $>$ chi 2 & 0.0000 & 0.0000 & 0.0000 \\
\hline
\end{tabular}


Table 9: Efficiency (average profits)

\begin{tabular}{|c|c|c|c|c|c|}
\hline & Profit & All Degrees & D1 & $\mathrm{D} 2$ & D3 \\
\hline \multirow{5}{*}{ VCM } & All Networks & $\begin{array}{c}70.401 \\
(17.693) \\
\end{array}$ & $\begin{array}{c}70.368 \\
(17.888) \\
\end{array}$ & $\begin{array}{c}68.054 \\
(17.938) \\
\end{array}$ & $\begin{array}{c}73.420 \\
(16.718) \\
\end{array}$ \\
\hline & Complete net. & $\begin{array}{c}73.647 \\
(16.953)\end{array}$ & \multirow{4}{*}{\multicolumn{2}{|c|}{$\begin{array}{c}68.9 \\
(18.184) \\
66.532 \\
(17.407)\end{array}$}} & $\begin{array}{c}73.647 \\
(16.953)\end{array}$ \\
\hline & Circle & $\begin{array}{c}68.9 \\
(18.184)\end{array}$ & & & \\
\hline & Line & $\begin{array}{c}66.046 \\
(16.974)\end{array}$ & & & \\
\hline & Star & $\begin{array}{c}73.880 \\
(17.447)\end{array}$ & & & $\begin{array}{c}72.397 \\
(15.630)\end{array}$ \\
\hline \multirow{5}{*}{ PUN } & All Networks & $\begin{array}{c}67.996 \\
(26.030)\end{array}$ & $\begin{array}{c}73.977 \\
(22.082)\end{array}$ & $\begin{array}{c}59.795 \\
(25.897)\end{array}$ & $\begin{array}{c}72.452 \\
(27.138)\end{array}$ \\
\hline & Complete net. & $\begin{array}{c}73.649 \\
(26.746)\end{array}$ & & \multirow{4}{*}{$\begin{array}{c}62.035 \\
(24.756) \\
55.763 \\
(27.406)\end{array}$} & $\begin{array}{c}73.649 \\
(26.746)\end{array}$ \\
\hline & Circle & $\begin{array}{c}62.035 \\
(24.756)\end{array}$ & & & \\
\hline & Line & $\begin{array}{c}61.413 \\
(25.609)\end{array}$ & $\begin{array}{c}67.064 \\
(22.320)\end{array}$ & & \\
\hline & Star & $\begin{array}{c}76.570 \\
(23.115)\end{array}$ & $\begin{array}{c}79.739 \\
(20.165)\end{array}$ & & $\begin{array}{c}67.062 \\
(28.302)\end{array}$ \\
\hline
\end{tabular}

Standard deviation between brackets. 
Table 10: Efficiency (profits) analysis

\begin{tabular}{lc} 
& $(9)$ \\
\hline Intercept & $69.209^{* * *}$ \\
& $(2.945)$ \\
Period & $0.423^{* * *}$ \\
& $(0.061)$ \\
CI & $-11.615^{* * *}$ \\
& $(4.065)$ \\
LI & $-12.236^{* * *}$ \\
& $(3.962)$ \\
ST & 2.920 \\
& $(4.190)$ \\
\hline CI - LI & 0.621 \\
& $(3.962)$ \\
CI - ST & $-14.535^{* * *}$ \\
& $(4.190)$ \\
LI - ST & $-15.156^{* * *}$ \\
& $(4.090)$ \\
\hline \#Obs & 2,880 \\
Prob $>$ chi2 & 0.0000 \\
R-sq: within & 0.0173 \\
& between \\
$\quad$ overall & 0.1353 \\
& 0.0756
\end{tabular}


Figure 3: Profits with punishments

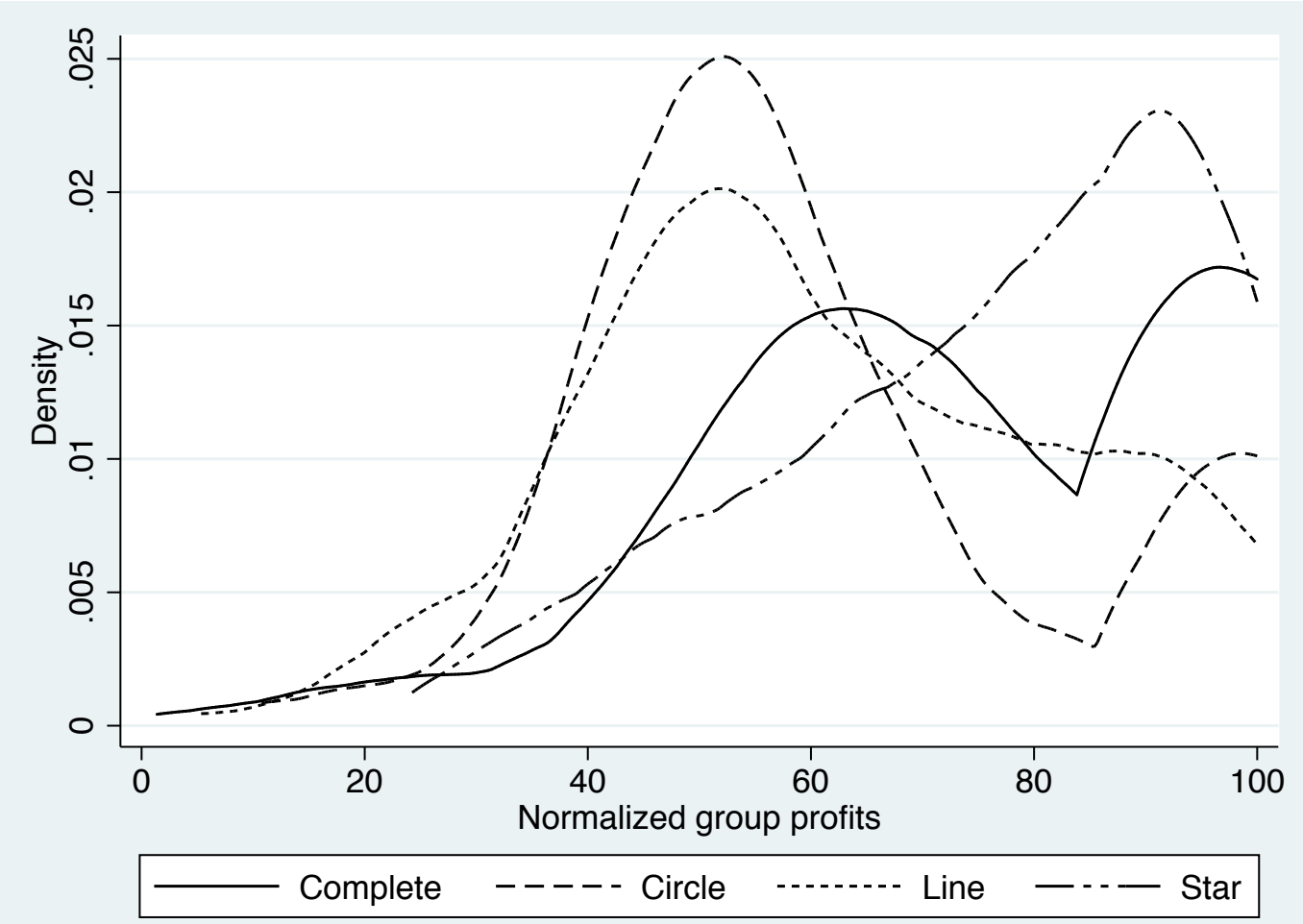


Figure 4: Profits across networks and games

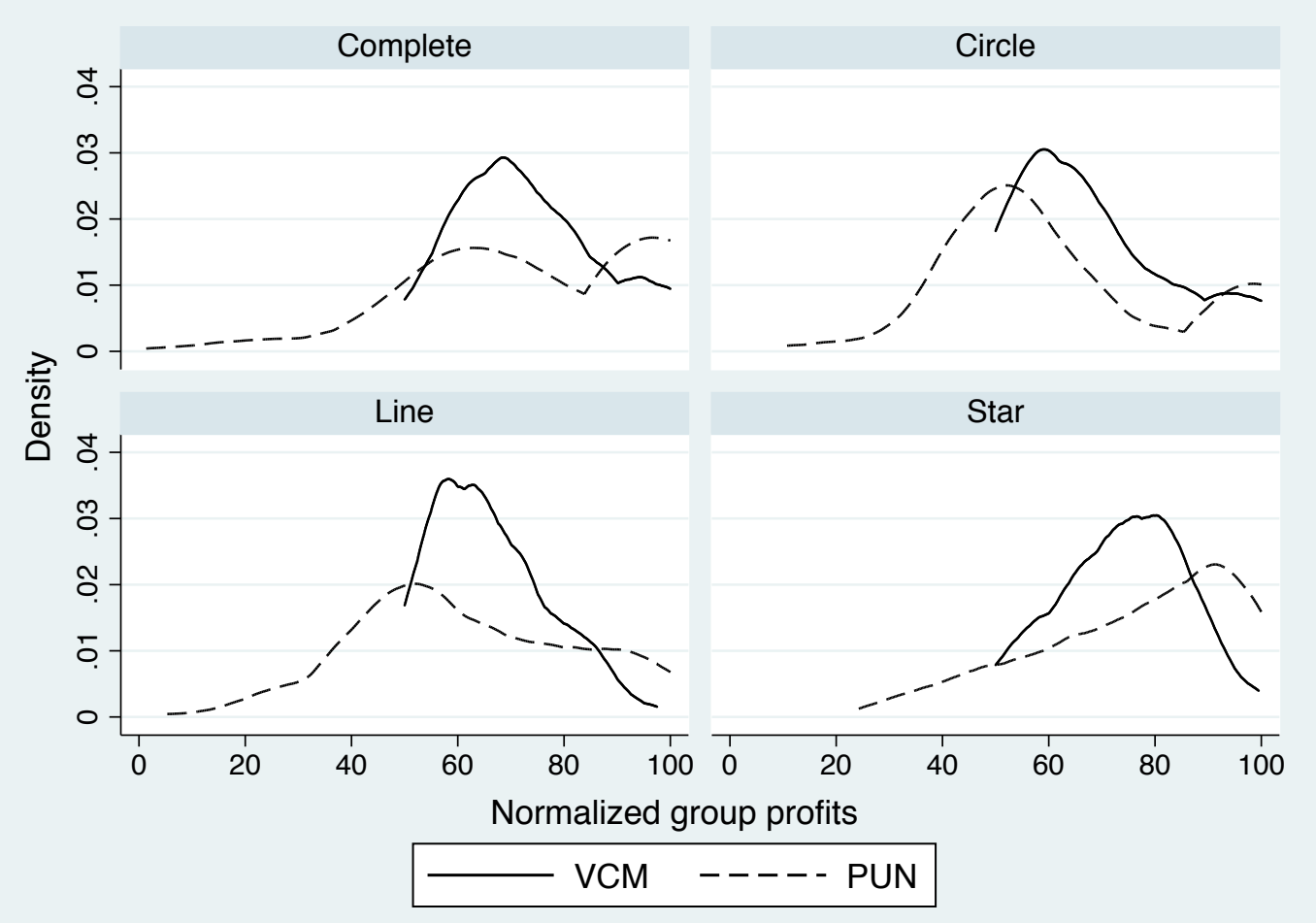




\section{Appendix: Experimental instructions ${ }^{28}$}

\section{VCM Instructions}

The aim of this Experiment is to study how individuals make decisions in certain contexts. The instructions are simple. If you follow them carefully you will earn a non-negligible amount of money in cash at the end of the experiment. Individual payments will remain private, as nobody will know the other participants' payments. Any communication among you is strictly forbidden and will result in an immediate exclusion from the Experiment.

1.- The experiment consists of 20 rounds. In each round you are member of the same group of 4 participants. Group composition is randomly determined at the beginning of the experiment and does not vary along it. You will not know the identities of the other group members.

2.- At the beginning of the experiment, you will be assigned a player number, which can be 1, 2, 3 or 4 . This number will not change along all the experiment. Therefore, in your group there will be a player 1, a player 2, a player 3 and a player 4 . You will be one of them.

3.- At each round, each participant receives an endowment of 50 ECUS. Your unique decision consists on choosing how many of them you assign to the Group Account. The remaining ECUS will remain in you Private Account.

4.- After these decisions are made, each participant will receive information about the assignments to the Group Account made by some other group members. This information is summarized in the following figure:

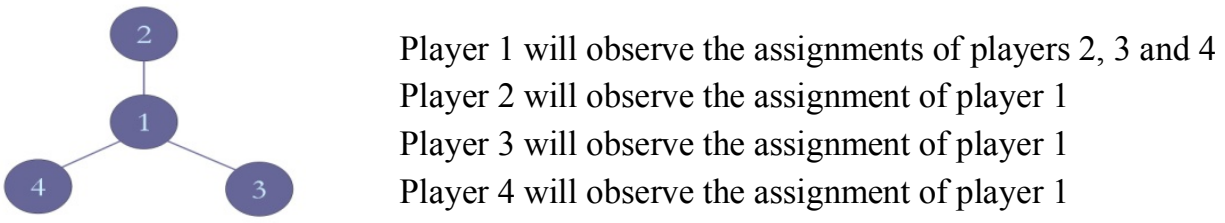

5.- Your round profits comes both from the group and private accounts. To calculate the benefit of the Group Account we first sum the assignments that all group members have made to the Group Account (i.e., we sum the assignments of players 1, 2, 3 and 4 to the Group Account). This sum of assignments to the Group Account is multiplied by 2, and divided in 4 equal shares (one share for each member of the group).

6.- The Private Account benefit equals your assignment to the Private Account and does not depend on the decisions made by the other players.

7.- To summarize, your benefit in a given round is determined as follows:

$\begin{aligned} & \text { Individual Benefit = } \text { Benefit from the Group Account + Benefit from the Private Account } \\ &(0.5 x \text { Sum of assignments of } \quad(50 \text { ECUS - my assignment to } \\ &\text { my group to the Group Account }) \\ &\text { the Group Account })\end{aligned}$

8.- At the end of every round, you will get information about current and past profits. The information consists of the benefit you obtain from the Group Account, the benefit you obtain from the Private Account, your total individual benefit and your accumulated benefit up to that moment.

9.- At the beginning of the experiment, just by showing up, you will start with an accumulated benefit of 500 ECU (Experimental Currency Units). The benefits that you obtain during the experiments will be added to that amount. At the end of the experiment your cumulative profits (plus the showing-up fee) will be privately paid in cash at the exchange rate of $100 \mathrm{ECU}=€ 1$.

\footnotetext{
${ }^{28}$ We provide the experimental instruction of the star treatment. The instructions of the other treatments (complete network, circle and line) are analogous and just differ in point 4 . Instructions are translated from Spanish. Original instructions are available from authors upon request.
} 


\section{PUN Instructions ${ }^{29}$}

1.- It starts the second part of the experiment, that consists of 20 rounds. After these rounds the experiment will definitely end. At all rounds you will remain in the same group of 4 participants that you were assigned at the beginning of the experiment. Each member of the group will keep the same player number $(1,2,3$ or 4$)$.

2.- In this part of the experiment, at each round you will be asked to take some decisions. The first decision is identical to what you have been doing up to now, that is, at each round, each participant receives an endowment of 50 ECUS, and you will be asked to decide how many of them you assign to the Group Account. The remaining ECUS will remain in you Private Account.

3.- Your preliminary benefit from the round is determined in the same way as in the first part of the experiment

Preliminary Benefit $=$ Benefit from the Group Account + Benefit from the Private Account

4.- However at each round, after all assignments have been done, each group member will be asked to make additional decisions. Recall that each member of the group receives information about the assignments to the Group Account of some of the other members of the group

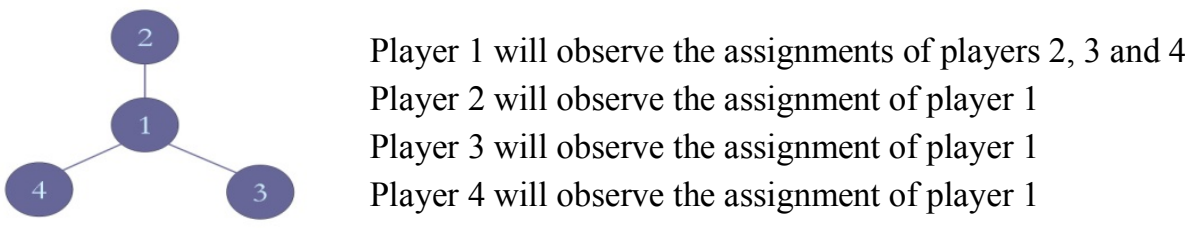

5.- Once this information have been observed, each participant can send from 0 to 10 points $(0$ and 10 included) to each of the members of the group he observes, that is:

Player 1 decides how many points (from 0 to 10 ) to send to player 2, how many (from 0 to 10 ) to send to player 3 and how many (from 0 to 10 ) to send to player 3 .

Player 2 decides how many points (from 0 to 10 ) to send to player 1.

Player 3 decides how many points (from 0 to 10) to send to player 1.

Player 4 decides how many points (from 0 to 10 ) to send to player 1.

6.- When you send points to another participant you reduce his profits in the following way: Each point you send to a member of your group reduces by a $10 \%$ the Preliminary Profit he had achieved. Thus, if you send 0 points to another participant you do not alter his benefits; if you send him 1 point, you reduce his benefits by $10 \%$; if you send him 2 points, you reduce his benefits by $20 \%$, etc. Note that you will be asked to type a number from 0 to 10 (sent points) for each of the members of the group that you observe. If you do not want to affect the benefits of someone, you just need to send him 0 points.

7.-Additionally, to send points is also costly for you. The higher the number of points you send to another participant, the higher your cost will be. The following table shows the cost (in ECUS) that you incur in order to send from 0 to 10 points to another participant:

\begin{tabular}{|l|l|l|l|l|l|l|l|l|l|l|l|}
\hline Sent points & $\mathbf{0}$ & $\mathbf{1}$ & $\mathbf{2}$ & $\mathbf{3}$ & $\mathbf{4}$ & $\mathbf{5}$ & $\mathbf{6}$ & $\mathbf{7}$ & $\mathbf{8}$ & $\mathbf{9}$ & $\mathbf{1 0}$ \\
\hline Cost for you & 0 & 2 & 4 & 8 & 12 & 18 & 24 & 32 & 40 & 50 & 60 \\
\hline
\end{tabular}

If you sent points to more than one participant, this calculation must be done separately for each of them. That is, for example, if you observe three group members and send 2 points to a group member, it costs you 4 ECUS; if you send 9 points to another group member, it costs you 50 ECUS; and if you send 0 points to the remaining group member, it is costless for you. In the example, your total cost for sending points would be 54 ECUS $(4+50+0)$.

\footnotetext{
${ }^{29}$ First, subjects were informed that they are going to play additional rounds of a modified game. They are informed that, if someone wanted to leave with her accumulated earnings up to that moment, she could freely do it. All subjects remained in the lab.
} 
8.- Therefore your benefit of a round will be affected both by the total number of points that other member of your group have sent you and by the points you have sent to each of them. To obtain the benefit of a round we take first the preliminary benefit (Benefit from the Group Account + Benefit from the Private Account). Such preliminary benefit is first reduced by a percentage associated to the total number of points you have received (Note: for each received point it is reduced by $10 \%$ and the maximal possible reduction is $100 \%$ ). Next, you must subtract from your reduced benefit your total cost for sending points. That is to say:

A) If you have received 10 or more points, all your preliminary benefit disappears $(100 \%$ reduction) and therefore, in the round you have losses equivalent to the total cost you have incurred in order to send points. Your round benefit is:

Round Benefit $=$ - (Total cost for sending points $)$

B) If you have received less than 10 points, your round benefit is:

$\left(\begin{array}{l}\text { Round } \\ \text { Benefit }\end{array}\right)=\left((\right.$ Preliminary benefit $\left.) \times \frac{10-(\text { total points received })}{10}\right)-\left(\begin{array}{c}\text { Total cost for } \\ \text { sending points }\end{array}\right)$

9.-Note that, if your total cost for sending points exceed your (possibly reduced) preliminary benefit, your round benefit could be negative. However, by your decisions, you can avoid such situations (of incurring possible losses).

10.- At the end of every round, you will get information about the current and past rounds. The information consists of the benefit you obtain from the Group Account, the benefit you obtain from the Private Account, your preliminary benefit, the total number of points you have received, the percentage of reduction of your preliminary benefit, the reduced preliminary benefit, the total number of points you have sent, tour total cost, your round benefit and your accumulated benefit up to that moment.

11.- Additionally, for participating in the second part of the experiment, you will also start with an accumulated benefit of 500 ECUS. The benefits that you obtain at each round will be added to that amount (or subtracted, in case you incur losses).

12.- At the end of the experiment your cumulative profits (plus the showing-up fee) of the whole experiment (that is, the sum of your benefits from the two parts of the experiment) will be privately paid in cash at the exchange rate of $100 \mathrm{ECU}=€ 1$. 